\title{
Thermal analysis of a polymorphic azo dye derived from 2-amino-5 nitrothiazole
}

Ana M.F. Oliveira-Campos, Maria Jovita Oliveira ${ }^{\mathrm{a}}$, Lígia M. Rodrigues, M. Manuela Silva and Michael J. Smith*

Centro de Química, Universidade do Minho, 4710-452 Braga, Portugal

${ }^{a}$ Inst. Polymers \& Composites, Dept. Polymer Eng., Univ Minho, 4800-058 Guimarães, Portugal

\begin{abstract}
An azo dye, derived from 2-amino-5-nitrothiazole and a substituted N,N-dimethyl aniline, was studied by various techniques. Two sets of proton signals were obtained by NMR in $\mathrm{CDCl}_{3}$ solution, suggesting that two polymorphs coexist, however only one set of signals is observed in DMSO solution. Differential scanning calorimetry and thermogravimetric analysis were used to confirm the existence of two forms. The events registered during thermal treatment of a sample were assigned to a glass transition, recrystallization and fusion of crystalline compounds. Hot-stage microscopy was used to obtain images of the dye samples at various stages of the heating program and these observations support the interpretation of the calorimetric results.
\end{abstract}

Keywords: Azo dye; Polymorphism; NMR; DSC; Hot-stage microscopy

\section{Introduction}

Heterocycles are extensively used in disperse dye chemistry [1, 2] in textile and non-textile applications such as in reprographics, functional dye and non-linear optical systems, photodynamic therapy and lasers.

When the synthesis of dyes of this type, 1 and 2, was accomplished [3], it was found that certain examples of dyes, in particular compound $1(\mathrm{R}=\mathrm{Et})$ showed two sets of proton resonances in deuteriochloroform solutions. These two independent proton resonances suggested the presence of two forms (two conformers, A and B) of (1) (Fig. 1). The compound mentioned was subjected to further NMR characterization and theoretical calculations were also carried out [4].

A molecule capable of forming more than one crystalline structure is said to display polymorphism. Different polymorphs have different arrangements of atoms within the unit cell and naturally this can have a profound effect on the physical and chemical properties of 
the substance. Polymorphism is a complex phenomenon, previously described in detail by Bernstein [5,6]. Polymorphism has also been observed in dyes and pigments and several examples are described in the literature [7]. The characterization of polymorphs by NMR has been reported by Chippendale [8] and Lyčka [9].

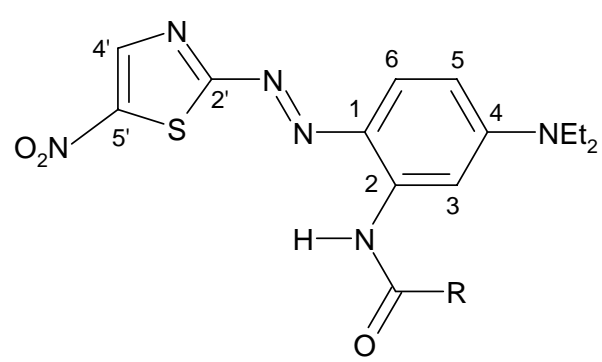

$1(\mathrm{R}=\mathrm{Et})($ Conformer $\mathbf{A})$

$2(\mathrm{R}=\mathrm{Me})($ Conformer $\mathbf{A})$

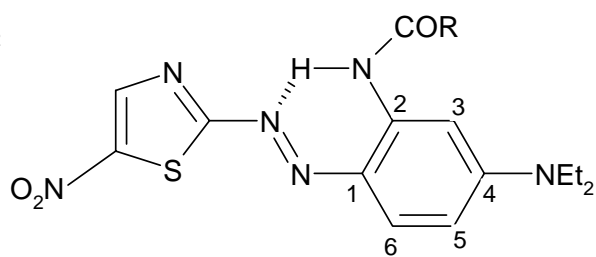

$1(\mathrm{R}=\mathrm{Et})($ Conformer $\mathbf{B})$

$2(\mathrm{R}=\mathrm{Me})($ Conformer $\mathbf{B})$

Fig. 1. Structures of compounds $\mathbf{1}$ and 2

In our previous study of compound 1, thermodynamic data indicated that the $\mathrm{B}$ form is favoured by DMSO solvation, probably due to the formation of intermolecular hydrogen bonding and also to the higher viscosity of this solvent [4].

In view of the possible existence of polymorphs of dye 2, further characterization was carried out using thermogravimetric analysis (TGA) and differential scanning calorimetry (DSC). The complementary technique of hot-stage microscopy was also applied to support our interpretation of calorimetric results.

Hot-stage microscopy (HSM) provides a qualitative method for screening substances for polymorphism. It is complementary to DSC because phase changes may be observed in HSM that are barely detectable by DSC. Thermal analysis provides quantitative information regarding the energies involved in phase changes.

\section{Experimental}

\section{1. $N M R$}

${ }^{1} \mathrm{H}$ NMR spectra were recorded at $300 \mathrm{MHz}$ and ${ }^{13} \mathrm{C}$ NMR spectra were determined at 75.4 $\mathrm{MHz}$ both on a Varian Unity Plus Spectrometer. Double resonance, Heteronuclear Multiple Quantum Coherence (HMQC) and Heteronuclear Multiple Bond Correlation (HMBC) experiments were carried out for complete assignment of proton and carbon signals in the NMR spectra.

\subsubsection{N-\{5-Diethylamino-2-[(5'-nitrothiazol-2’-yl)diazenyl]phenyl\}-acetamide (2) [4]}


${ }^{1} \mathrm{H}$ NMR (DMSO-d $)_{6} \delta(\mathrm{ppm}): 1.25\left(\mathrm{t}, J=7.5 \mathrm{~Hz}, 6 \mathrm{H}, 2 \mathrm{xCH}_{3}\right), 2.22\left(\mathrm{~s}, 3 \mathrm{H}, \mathrm{CH}_{3}\right), 3.61$ (q, J=7.2 $\mathrm{Hz}, 4 \mathrm{H}, 2 \mathrm{xCH}_{2}$ ), 6.83 (dd, J=2.7 and $\left.9.8 \mathrm{~Hz}, 1 \mathrm{H}, \mathrm{H}-4\right), 7.75$ (d, J=9.6 Hz, H-6), 7.90 (d, J=2.7 $\mathrm{Hz}, \mathrm{H}-3), 8.68$ (s, 1H, H-4'), 10.28 (br s, 1H, NH). ${ }^{13} \mathrm{C}$ NMR (DMSO-d $) \delta(\mathrm{ppm}): 12.39\left(\mathrm{CH}_{3}\right)$, $24.58\left(\mathrm{CH}_{3}\right), 45.36\left(\mathrm{CH}_{2}\right), 100.79$ (C-6), 110.90 (C-4), 129.15 (C-3), 132.01 (C-2), $141.36(\mathrm{C}-$ 1), 144.01 (C5'), 144.88 (C-4'), 155.63 (C-5), 169.10 (C=O), 181.15 (C-2').

$\left.{ }^{1} \mathrm{H} \mathrm{NMR} \mathrm{CDCl}_{3}\right) \delta(\mathrm{ppm}): 1.34\left(\mathrm{t}, J=7.5 \mathrm{~Hz}, 4 \mathrm{xCH}_{3}, \mathrm{~A}\right.$ and $\left.\mathrm{B}\right), 2.31$ and $2.34\left(2 \mathrm{x} \mathrm{s}, 2 \mathrm{x} \mathrm{CH}_{3}, \mathrm{~A}\right.$ and B), 3.60 (q, J=7.5 Hz, 4H, 2xCH $2, A$ and B), 6.54 (dd, J=2.4 and 9.9 Hz, H-5, A), 6.63 (dd, $\mathrm{J}=2.7$ and $9.9 \mathrm{~Hz}, \mathrm{H}-5, \mathrm{~B}), 7.58$ (d, J=9.3 Hz, H-6, B), 8.00 (d, J=9.6 Hz, H-6, A), 8.07 (d, $\mathrm{J}=2.1 \mathrm{~Hz}, \mathrm{H}-3, \mathrm{~A}), 8.31$ (d, J=2.7 Hz, H-3, B), 8.54 (s, H-4', B), 8.58 (s, H-4', A), 9.03 (br s, NH, A), 12.6 (br s, NH, B).

\subsection{Differential scanning calorimetry (DSC)}

Differential scanning calorimetry measurements were performed on a Mettler DSC 821e, calibrated with indium to ensure the accuracy of the calorimetric scale. The weighed sample $(0.5-1.5 \mathrm{mg})$ was characterized in a sealed $40 \mu \mathrm{L}$ aluminium cans with perforated lids and subjected to thermal analysis under a flowing argon atmosphere $\left(35 \mathrm{~mL} \mathrm{~min}^{-1}\right)$. Analysis was carried out under a variety of experimental conditions using an identical empty sample pan as reference.

Selected samples were heated from room temperature to $225{ }^{\circ} \mathrm{C}$ at a rate of $10{ }^{\circ} \mathrm{C} \mathrm{min}^{-1}$. These samples were subsequently cooled to $-60{ }^{\circ} \mathrm{C}$ temperature at a rate of $5{ }^{\circ} \mathrm{C} \min ^{-1}$. A second heating program, between $-60{ }^{\circ} \mathrm{C}$ and $225{ }^{\circ} \mathrm{C}$ at a rate of $10{ }^{\circ} \mathrm{C} \mathrm{min}{ }^{-1}$ was then applied. Other samples were subjected to different heating and cooling rates in order to identify optimum conditions.

\subsection{Thermogravimetric studies (TG)}

Samples for thermogravimetric characterization were located in open platinum crucibles and analyzed using a Rheometric Scientific TG1000 thermobalance operating under a flowing argon atmosphere $\left(28 \mathrm{~mL} \mathrm{~min}{ }^{-1}\right)$. A heating rate of $10{ }^{\circ} \mathrm{C} \mathrm{min}^{-1}$ was used and all samples were studied between 30 and $400{ }^{\circ} \mathrm{C}$.

\subsection{Hot stage microscopy studies}

The dried dye particles were mounted between a glass slide and a cover slip, placed on a Mettler FP 82 hot stage and observed with a polarized light Olympus BH2 microscope equipped with a digital camera. The calibration of the temperature scale was carried out in accordance with the manufacturer's instructions. 
The samples were heated to complete melting at a rate of $10^{\circ} \mathrm{C} \mathrm{min}^{-1}$, fast cooled at about 40 ${ }^{\circ} \mathrm{C} \min ^{-1}$ down to room temperature and re-heated again at $10{ }^{\circ} \mathrm{C} \mathrm{min}^{-1}$.

\section{Results and discussion}

\subsection{NMR spectra}

The NMR spectra for the dye 2 were obtained in $\mathrm{DMSO}-\mathrm{d}_{6}$ and in $\mathrm{CDCl}_{3}$, but the low solubility of the compound in chloroform prevented the acquisition of the ${ }^{13} \mathrm{C}$ spectrum in this solvent.

The spectrum in $\mathrm{CDCl}_{3}$ displays two sets of signals, as shown in fig. $2 \mathrm{~b}$ and described in the experimental part. The assignment was based on a similar example (fig.1, compound 1) where the proton and carbon resonances of each conformer were atributed by HMBC and HMQC, starting from the NH signals and assuming that the highest chemical shift corresponds to the $\mathrm{NH}$ involved in a hydrogen bond forming a six membered ring [4]. All the signals for our compound parallel those observed for compound 1 which would be expected from their structural similarity. The spectral data are consistent with the cohexistence of both conformers where conformer $\mathrm{B}$ was associated with the most acidic $\mathrm{NH}$ signal at $12.6 \mathrm{ppm}$ and for conformer A, the $\mathrm{NH}$ resonance shows at $9.03 \mathrm{ppm}$.

The ${ }^{1} \mathrm{H}$ NMR spectrum acquired in DMSO- $\mathrm{d}_{6}$, either at room temperature, 50 or $70{ }^{\circ} \mathrm{C}$, displayed only one set of signals. At room temperature very broad signals are observed for $\mathrm{NH}, 9.60 \mathrm{ppm}, \mathrm{H}-3,7.85$ ppm, and H-6, $7.75 \mathrm{ppm}$. When temperature is increased to $70{ }^{\circ} \mathrm{C}$ the $\mathrm{H}-3$ and $\mathrm{H}-6$ doublets become sharp, 7.90 and $7.75 \mathrm{ppm}$, respectively. The $\mathrm{NH}$ signal shifts from $9.60 \mathrm{ppm}$ at room temperature to 10.10 and 10.28 at $50^{\circ}$ and $70{ }^{\circ} \mathrm{C}$, respectively and sharpens slightly. The appearance and the chemical shifts of H-4', H-5 and of the aliphatic protons do not change with temperature. These observations may be consistent with exchange between the two conformers. (Fig. 2b).

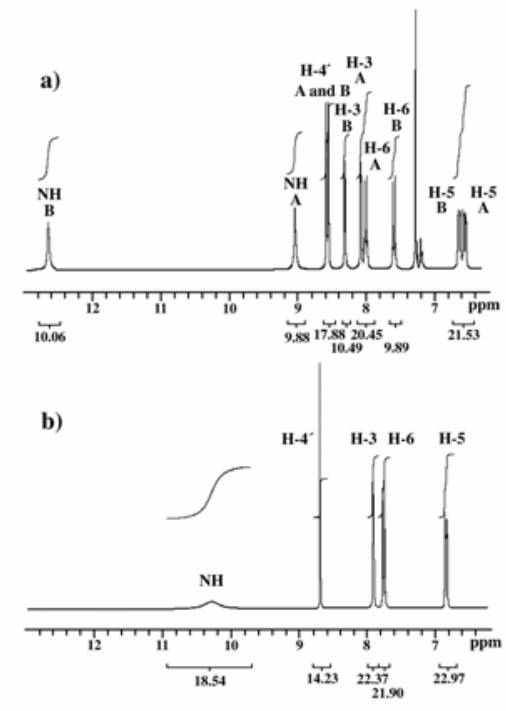

Fig. 2. ${ }^{1} \mathrm{H}$ NMR spectra in $\mathrm{CDCl}_{3}$ (a), RT and in $\mathrm{DMSO}$ b), $70{ }^{\circ} \mathrm{C}$ ) 


\subsection{Thermal analysis}

The thermal behaviour of solid samples was studied during heating cycles using thermogravimetry and differential scanning calorimetry. The results of the thermogravimetric study are illustrated in Fig. 3 and confirm that the material suffers thermal degradation at temperatures above about $240{ }^{\circ} \mathrm{C}$. This value for onset of degradation is obtained from the point of intersection of the extrapolated pre-weight-loss baseline with the tangent to the curve produced by the decomposition reaction. The maximum error associated with this process is estimated as about $5{ }^{\circ} \mathrm{C}$. Observations using both DSC and thermogravimetric techniques are consistent with a minimum thermal stability of $240 \pm 5{ }^{\circ} \mathrm{C}$ for dye 2 . The DSC curves of 2 were obtained using the heating programs described in the experimental section and a typical example is shown in Fig. 4. This figure illustrates the results obtained by heating from room temperature to $225^{\circ} \mathrm{C}$. A sample of the dye 2, as prepared, subjected to a heating rate of 10 ${ }^{\circ} \mathrm{C} \min ^{-1}$, was observed to undergo fusion at an extrapolated onset temperature of 204.6 $\pm 0.1^{\circ} \mathrm{C}$. The enthalpy of melting was $\Delta_{\text {fus }} \mathrm{H}=-164.0 \pm 0.1 \mathrm{~mJ}$ or $\Delta_{\text {fus }} \mathrm{H}=-35.7 \pm 0.1 \mathrm{~J}$ $\mathrm{mol}^{-1}$. Other samples of the same dye, subjected to different heating rates, showed similar thermal behaviour confirming the reproducibility of results and the expected dependence of onset temperature on heating rate. The first heating cycle confirms that the sample as prepared adopts the structure of the more stable form. This sample was subsequently cooled to $-60{ }^{\circ} \mathrm{C}$, at a cooling rate of $5{ }^{\circ} \mathrm{C} \mathrm{min}^{-1}$, and no phase transitions were observed. The results for the second heating cycle, at a rate of $10{ }^{\circ} \mathrm{C} \min ^{-1}$ (Fig. 5), confirmed the presence of a low intensity endothermic event at $54.2 \pm 0.1{ }^{\circ} \mathrm{C}$, a broad exothermic peak with an onset of $111.5 \pm 0.1{ }^{\circ} \mathrm{C}$ and an endothermic peak with an onset of $183.6 \pm 0.1{ }^{\circ} \mathrm{C}\left(\Delta_{\text {fus }} \mathrm{H}=-29.9 \pm 0.1 \mathrm{~J}\right.$ $\mathrm{mol}^{-1}$ ). These results suggest that fast cooling of the dye melt leads to the formation of a metastable amorphous solid as confirmed by hot-stage microscopy (Fig. 6c). On heating this solid undergoes a weakly discernible glass transition followed by crystallization. The thermal events recorded during analysis [10] were therefore assigned to a glass transition $(54.2 \pm 0.1$ $\left.{ }^{\circ} \mathrm{C}\right)$, recrystallization $\left(111.5 \pm 0.1{ }^{\circ} \mathrm{C}\right)$ and fusion $\left(183.6 \pm 0.1{ }^{\circ} \mathrm{C}\right)$. These observations are consistent with NMR measurements and with a previous publication which describes the results obtained with another azo dye [4]. Although melting points of polymorphs can be very close $[5,11]$, in this case the melting point of the metastable polymorph lies significantly below that of the thermodynamically stable form. 


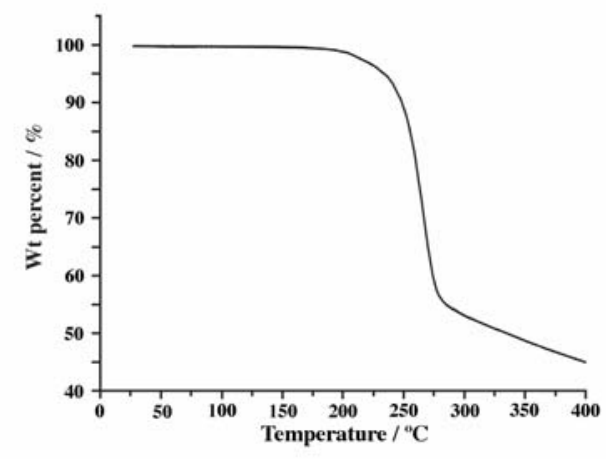

Fig. 3. Thermogravimetry curve for dye 2

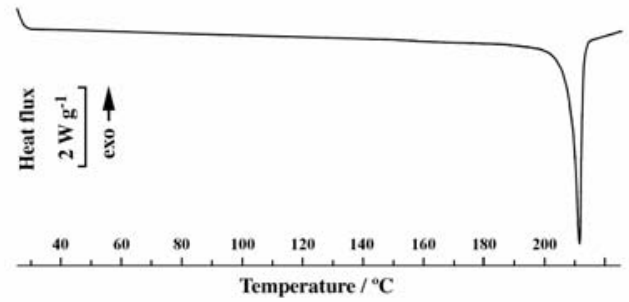

Fig. 4. DSC heating run for dye 2 at $10{ }^{\circ} \mathrm{C} \mathrm{min}^{-1}$

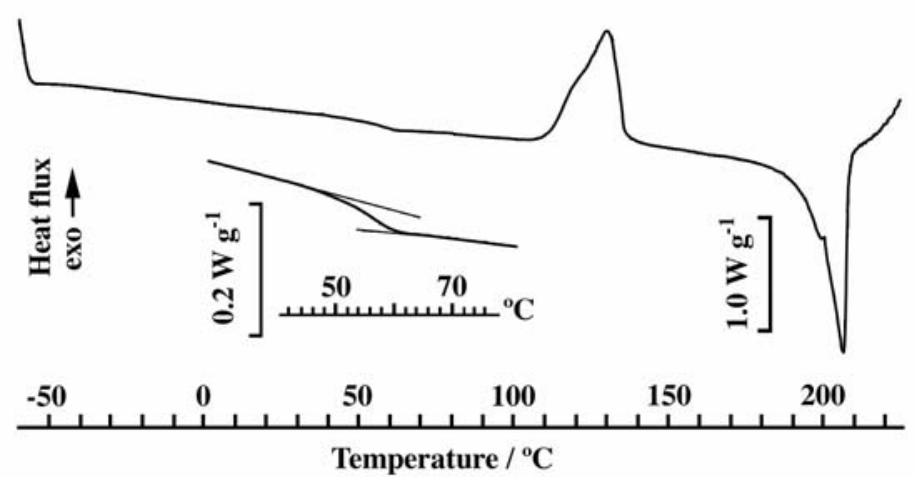

Fig.5. Second DSC heating run for dye 2, starting from an undercooled melt.

\subsection{Microscopical analysis}

Hot-stage microscopy was used to obtain images of the dye samples at various stages of the heating program. The dye particles, as prepared, have an acicular form (Fig. 6a) that remains unchanged up to the melting temperature at about $208^{\circ} \mathrm{C}$ (fig. 6b). Fast-cooling of the melt did not crystallize the material (Fig. 6c), however, during the second heating the material recrystallized at about $145^{\circ} \mathrm{C}$ forming highly birefringent acicular crystals (Fig. 6d), radiating outwards from the original droplet. The recrystallized material melted at approximately the same temperature as that observed in the first heating program. 


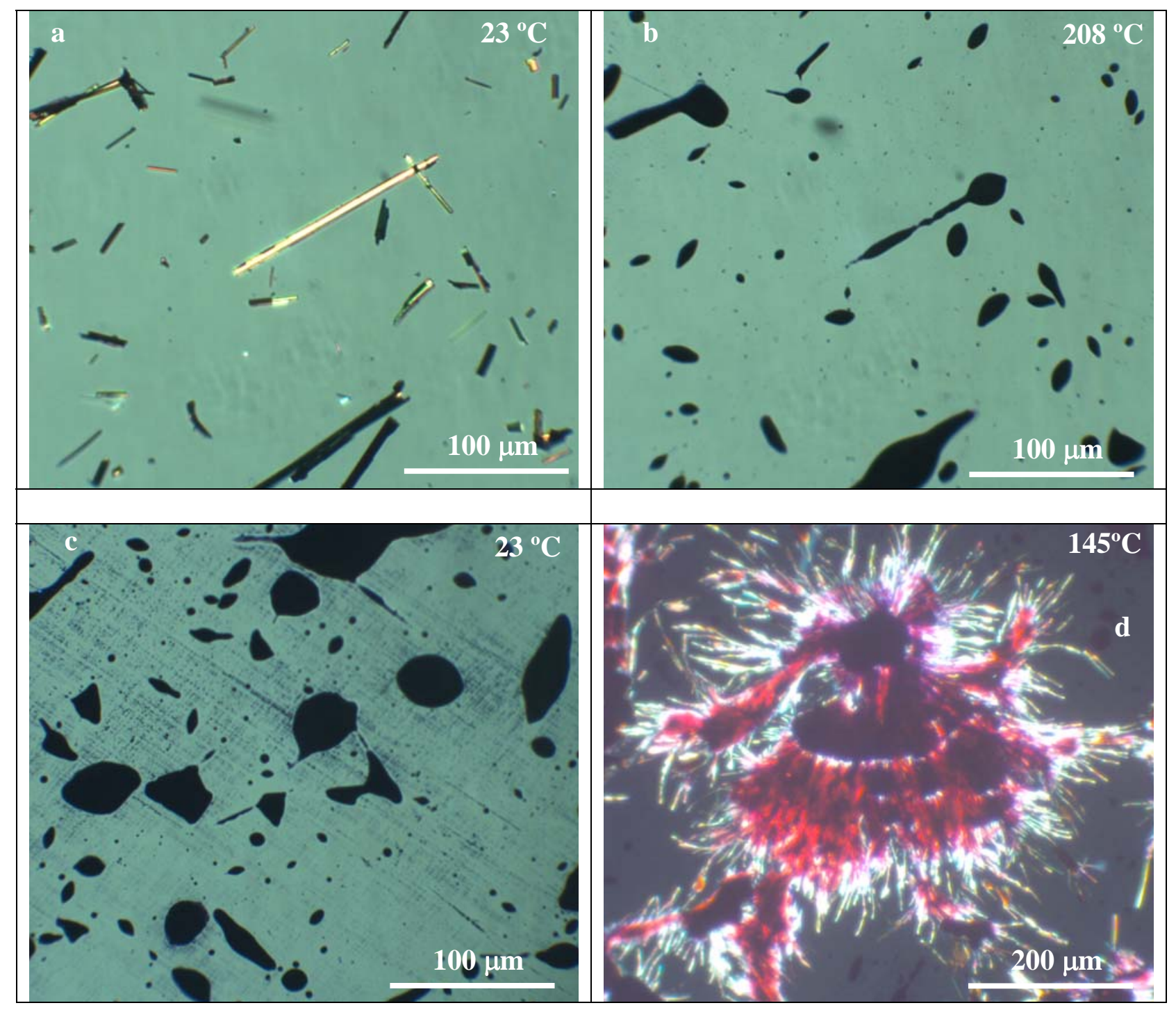

Fig. 6 Photomicrographs of the dye 2. a- Dye 2 as prepared; b-Melt; c-Fast-cooled; dRecrystallized from the melt.

\section{Conclusions}

Thermal analysis has been used to further characterize a polymorphic system of an azo dye after preliminary studies by ${ }^{1} \mathrm{H}$ NMR identified an anomalous behaviour. The information obtained from the melting curves of the organic dye compounds by DSC show two polymorphs with quite close melting points. The existence of two different crystalline forms was also confirmed visually by hot-stage microscopy.

\section{Acknowledgements}

The authors thank Fundação para a Ciência e Tecnologia (FCT) (POCTI-SFA-3-686) and FEDER (Portugal) for financial assistance. 


\section{References}

[1] M.A. Weaver and L. Shuttleworth, Dyes and Pigments 3 (1982) 81.

[2] A.D. Towns, Dyes and Pigments 42 (1999) 3.

[3] P.C. Miranda, L.M. Rodrigues, M.S.T. Gonçalves, S.P.G. Costa, R. Hrdina and A.M.F. Oliveira-Campos, Advances in Colour Science and Technology 4(1) (2001) 21. http://hdl.handle.net/1822/1545

[4] L.M. Rodrigues, S. Gupta, A.M.F. Oliveira-Campos, A.E. da Hora Machado and A. Silva, J. Mol. Struct. 738 (2005) 241. http://hdl.handle.net/1822/1052

[5] J. Bernstein, R.J. Davey and J-O Henck, Angew. Chem. Int. Ed. 38 (1999) 3440.

[6] J. Bernstein, Polymorphism in Molecular Crystals, IUCr Monographs on Crystallography, 14, Clarendon Press, Oxford, 2002.

[7] J. Bernstein, Polymorphism in Molecular Crystals, IUCr Monographs on Crystallography, 14, Clarendon Press, Oxford, 2002, p.257.

[8] G. McGeorge, R.K. Harris, A.M. Chippendale and J.F. Bullock, J. Chem. Soc., Perkin Trans. 2 (1996) 1733.

[9] A. Lycka, An. Rep. on NMR Spectroscopy, Vol. 42, Academic Press, London, 2000, p.1.

[10] G. Widmann, Thermochimica Acta 112 (1987) 137.

[11] E. Aret, H. Meekes, E. Vlieg and G. Deroover, Dyes and Pigments 72 (2007) 339. 